\title{
Ефективність протизлукових препаратів при плановому і ургентному ентеролізі
}

\begin{abstract}
Мета роботи: вивчити і порівняти результати лікування хворих зі злуковою хворобою очеревини після планових і ургентних оперативних втручань, яким проведено роз’єднання зрощень і використано препарат “Дефенсаль”. Одним із шляхів профілактики післяопераційних злук є не тільки розробка сучасних методів оперативних втручань, інтактних шовних матеріалів та сучасних імплантатів, а пошук нових методів запобігання післяопераційним зрощенням за допомогою протизлукових препаратів. Матеріали і методи. За період з 2013 по 2019 роки обстежено та проліковано 80 хворих зі злуковою хворобою, яким проведено роз’єднання зрощень, віком від 21 до 79 років. Хворих розділили на групи: 1) в групу контролю ввійшли 20 хворих, яким із хворобою зрощень очеревини, інцізійними грижами великих розмірів проведено планове оперативне і консервативне лікування загальноприйнятими методиками; 2) в другій групі (20 хворих) проведено планове оперативне втручання і роз’єднання зрощень з використанням препарату “Дефенсаль”; 3) третю групу склали 20 хворих, яким із гострою злуковою тонкокишковою непрохідністю проведено ургентний ентероліз без використання препарату “Дефенсаль”; 4) четверта група - 20 хворих, яким із гострою злуковою тонкокишковою непрохідністю проведено ургентний ентероліз з використанням препарату “Дефенсаль”. Результати досліджень та їх обговорення. Добрі безпосередні, короткотермінові і віддалені результати терміном спостереження до 6 років отримано у другій групі після проведення планових оперативних втручань і використання препарату “Дефенсаль”. Проте в четвертій групі хворих після ургентного ентеролізу і використання препарату видно покращення безпосередніх результатів, проте віддалені результати практично не відрізняються від третьої групи хворих. Досягти покращення результатів можна при використанні комплексного підходу до профілактики і лікування хвороби зрощень очеревини, використанні сучасних і нових протиспайкових препаратів.
\end{abstract}

Ключові слова: злукова хвороба; препарат “Дефенсаль”; ентероліз.

Постановка проблеми і аналіз останніх досліджень та публікацій. Злукова хвороба очеревини є однією з тяжких і невирішених проблем хірургії. Кількість пацієнтів постійно зростає, що зумовлено зростанням кількості і об’єму оперативних втручань на органах черевної порожнини. Після повторних лапаротомій кількість пацієнтів із злуковою хворобою очеревини та її ускладненнями зростає. За даними авторів [1-4], після однієї лапаротомії злуки розвиваються у 10,4 \% хворих, а після повторних - у 70-93 \%. Утворення фібрину - реакція очеревини на травму. Однак за певних умов порушення фібринолізу формується злукова хвороба очеревини різного ступеня поширення та виразності злук. Перитонеальні злуки виявляють у 93 - 100 \% пацієнтів, після оперативних втручань на черевній порожнині, хоча більшість 3 них має безсимптомний перебіг.

Злуки - це основна причина гострого чи хронічного тазового болю, безпліддя в гінекології, абдомінального болю і злукової кишкової непрохідності в хірургії та [7, 8, 9]. За даними різних авторів, злукова хвороба очеревини у 32 \% випадках спричиняє гостру кишкову непрохідність $[12,13$, 14], $з$ них у 75 \% випадків - тонкокишкову непрохідність [15]. У 5 - 18 \% прооперованих хворих спостерігають клінічні вияви різного ступеня виразності, пов'язані зі злуковим процесом у черев- ній порожнині, близько 3,8 \% таких пацієнтів потребують повторної госпіталізації та оперативних втручань [14]. Ентероліз при клінічно маніфестованій злуковій хворобі очеревини - необхідна і рутинна процедура, але він спричиняє формування нових злук, а 12 - 19 \% пацієнтів потребують повторних операцій [9].

Профілактика злукової хвороби надзвичайно важлива. Одним із шляхів профілактики післяопераційних злук $€$ не тільки розробка сучасних методів оперативних втручань, інтактних шовних матеріалів та сучасних імплантатів, а пошук нових методів запобігання післяопераційних зрощень за допомогою протизлукових препаратів.

Найвідомішими протизлуковими препаратами $€$ сполуки на основі карбоксиметилцелюлози та гіалуронової кислоти, полісахаридів, які утворюють бар’єр між органами черевної порожнини, запобігаючи випаданню на них фібрину та склеюванню $[10,11]$.

Властивості гіалуронової кислоти: механічний вплив: бар’єр/лубрикація; зволожувальні властивості: високий ступінь зв'язування води; загоювальні властивості: нормалізація міграції і проліферації клітин; заповнення простору; допоміжна функція: переривання запального каскаду.

DEFENSAL (ДЕФЕНСАЛЬ) являє собою стерильну апірогенну прозору безбарвну або блідожовту рідину одноразового застосування на осно- 
ві гіалуронової кислоти нетваринного походження. Використовується в процесі хірургічного лікування в якості інстиляту для зменшення утворення зрощень після операцій на органах черевної порожнини, малого таза, плевральної порожнини та інше. Складається з трьох складових частин, які впливають на основні ланки патогенезу злук: гіалуронова кислота (полісахарид, що входить до складу позаклітинної рідини сполучної тканини, забезпечує роз’єднання листків очеревини в критичний період утворення злук), декаметоксин (антисептик широкого спектра дії, має протизапальну та антиексудативну дію, забезпечує зниження локальної запальної відповіді в зоні оперативного втручання), сукцинат натрію (має високу буферну ємність, забезпечує антигіпоксичну та антиоксидантну дію).

Показання для використання протизлукових препаратів нечіткі, немає зрозумілих алгоритмів та інструкцій для застосування в загальній хірургії. Через це більшість хірургів уникає їх використання [3, 5, 6, 8].

Мета роботи: вивчити і порівняти результати лікування хворих зі злуковою хворобою очеревини після планових і ургентних оперативних втручань, яким проведено роз’єднання зрощень і використано препарат “Дефенсаль”.

Матеріали і методи. За період з 2013 по 2019 р. обстежено та проліковано 80 хворих зі злуковою хворобою, яким проведено роз'єднання зрощень, віком від 21 до 79 років. Середній вік хворих складав $(51,1 \pm 12,4)$ року $(m=1,25), 69 \%$ хворих припало на працездатний вік до 60 років.

Хворі розділені на такі групи:

1) в групу контролю ввійшли 20 хворих, яким із хворобою зрощень очеревини, інцізійними грижами великих розмірів проведене планове оперативне і консервативне лікування загальноприйнятими методиками; 2) в другій групі (20 хворих) проведено планове оперативне втручання і роз’єднання зрощень з використанням препарату “Дефенсаль”; 3) третю групу склали 20 хворих, яким із гострою злуковою тонкокишковою непрохідністю проведено ургентний ентероліз без використання препарату “Дефенсаль”; 4) четверта група - 20 хворих, яким із гострою злуковою тонкокишковою непрохідністю проведено ургентний ентероліз з використанням препарату “Дефенсаль”.

Поширення злукового процесу оцінювали згідно з класифікацією О. І. Бліннікова [15]:

I стадія - локальний злуковий процес, обмежений ділянкою післяопераційного рубця або частиною черевної порожнини, поширених не більше як на один поверх, за відсутності злук на інших ділянках;
II стадія - локальний злуковий процес у поєднанні з поодинокими злуками на інших ділянках;

III стадія - злуковий процес, поширений на 1/3 черевної порожнини;

IV стадія - дифузний злуковий процес, поширений на 2/3 черевної порожнини.

Для достовірності даних хворих в основну i контрольну групу відібрали з III і IV стадіями злукового процесу. За міжнародною класифікацією PAI (Peritoneal adhesion index) мінімум 5 із 9 ділянок живота в злуковому процесі.

Тяжкість злукового процесу оцінювали згідно 3 класифікацією Q. Zeng та співавт. [14]:

0 ступінь - відсутність злук;

1-й ступінь — найменш тяжкі: тонкі, аваскулярні, прозорі, пухкі, легко роз’єднуються тупим шляхом;

2-й ступінь - середньої тяжкості: середньої товщини та прозорості, частково васкуляризовані;

3-й ступінь - украй тяжкі: дуже щільні та високоваскуляризовані.

У дослідження включені хворі з 2 і 3 ступенем тяжкості злук.

Результати досліджень та їх обговорення. Згідно з TASC (2000р.), оцінку результатів лікування проводили за стандартизованими часовими інтервалами, рекомендованими хірургами і серцево-судинними хірургами: безпосередні результати - протягом 30 днів, короткотермінові результати - від 1 до 6 місяців по операції, проміжні результати - від 12 до 24 місяців по операції, віддалені результати - від 2-х років після операції.

Оцінка післяопераційного періоду наведена в таблиці 1:

Критерії оцінки безпосередніх результатів лікування. Критеріями оцінки лікування хвороби до 30 днів по операції $є$ пасаж кишечника (евакуація контрасту через 24 год - головний критерій), тривалість стаціонарного лікування, відновлення працездатності.

Критерї оцінки короткотермінових, проміжних і віддалених результатів лікування. Безумовними критеріями оцінки лікування хвороби зрощень у проміжному і віддаленому періоді є пасаж кишечника (евакуація контрасту через 24 год), порушення функції кишечника (закрепи, метеоризм), відчуття кишкового дискомфорту, наявність больового синдрому, астенічного синдрому, стаціонарне лікування в терапевтичному або хірургічному відділі з приводу злукової хвороби, відсутність повторних оперативних втручань із приводу злукових непрохідностей, рецидивних вентральних гриж (табл. 2).

Результати лікування груп хворих наведено в таблиці 3. 
Таблиця 1. Оцінка післяопераційного періоду

\begin{tabular}{||l|c|c|c||}
\hline \multirow{2}{*}{\multicolumn{1}{c|}{ Критерії }} & \multicolumn{3}{c||}{ Результат } \\
\cline { 2 - 4 } & добрий & задовільний & незадовільний \\
\hline Біль у черевній порожнині & відсутній & легкої інтенсивності & виражений \\
\hline Нудота & відсутня & легкої інтенсивності & виражена \\
\hline Відновлення (поява) перистальтики & до1 доби & до 2 доби 2 доби \\
\hline Відходження газів & до 2 доби & до 3 доби & після 3 доби \\
\hline Перше самостійне випорожнення & до 3-4 доби & до 5-6 доби & після 5-6 доби \\
\hline \hline
\end{tabular}

Таблиця 2. Оцінка короткотермінових, проміжних і віддалених результатів лікування

\begin{tabular}{|c|c|c|c|}
\hline \multirow{2}{*}{ Критерії } & \multicolumn{3}{|c|}{ Результат } \\
\hline & добрий & задовільний & незадовільний \\
\hline Больовий синдром & відсутній & легкої інтенсивності & виражений \\
\hline Пасаж кишечника & до1 доби & до 2 доби & після 2 доби \\
\hline Відчуття кишкового дискомфорту & відсутній & легкої інтенсивності & виражений \\
\hline Астенічний синдром & відсутній & легкої інтенсивності & виражений \\
\hline Стаціонарне лікування & відсутнє & $\begin{array}{c}\text { 1-2 рази в } \\
\text { терапевтичному відділі }\end{array}$ & $\begin{array}{c}\text { хірургічне } \\
\text { лікування }\end{array}$ \\
\hline
\end{tabular}

Таблиця 3. Результати лікування груп хворих

\begin{tabular}{|c|c|c|c|c|}
\hline \multicolumn{2}{|c|}{ Результати } & Добрий & Задовільний & Незадовільний \\
\hline \multirow{4}{*}{$\begin{array}{l}\text { Післяопераційний } \\
\text { період і безпосередні }\end{array}$} & I - контрольна & $12(60 \%)$ & $6(30 \%)$ & $2(10 \%)$ \\
\hline & II & $16(80 \%)$ & $4(20 \%)$ & - \\
\hline & III & $8(40 \%)$ & $7(35 \%)$ & $5(25 \%)$ \\
\hline & IV & $10(50 \%)$ & $8(40 \%)$ & $2(10 \%)$ \\
\hline \multirow{4}{*}{ Короткотермінові } & I - контрольна & $10(50 \%)$ & $8(40)$ & $2(10 \%)$ \\
\hline & II & $15(75 \%)$ & $5(25 \%)$ & \\
\hline & III & $10(50 \%)$ & $6(30 \%)$ & $4(20 \%)$ \\
\hline & IV & $12(60 \%)$ & $4(20 \%)$ & $4(20 \%)$ \\
\hline \multirow{4}{*}{ Віддалені } & I - контрольна & $10(50 \%)$ & $8(40)$ & $2(10 \%)$ \\
\hline & II & $15(75 \%)$ & $5(25 \%)$ & \\
\hline & III & $8(40 \%)$ & $6(30 \%)$ & $6(30 \%)$ \\
\hline & IV & $9(45 \%)$ & $7(35 \%)$ & $5(35 \%)$ \\
\hline
\end{tabular}


3 даними таблиці 3, очевидна ефективність використання протизлукового препарату “Дефенсаль” у другій групі хворих після планових оперативних втручань. Проте в четвертій групі хворих після ургентного ентеролізу і використання препарату видно покращення безпосередніх результатів, проте відділені результати практично не відрізняються від третьої групи хворих. Слід чітко диференціювати хворих зі злуковою хворобою очеревини і маніфестуючими тонкокишковими непохідностями від планових ентеролізів.

\section{СПИСОК ЛІТЕРАТУРИ}

1. Current strategies and future perspectives for intraperitoneal adhesion prevention / C. Brochhausen, V. H. Schmitt, D. Hollemann [et al.] // J. Gastrointest. Surg. - 2012. - Vol. 16. - P. 1256-1274.

2. Post-operative adhesions after digestive surgery: their incidence and prevention: review of the literature / T. K. Rajab, M. Wallwiener, S. Talukdar [et al.] // J. Visc. Surg. - 2012. Vol. 149. - P. 104-114.

3. Antibiotic Guidelines 2015-2016. - Johns Hopkins. Treatment Recommendations For Adult Inpatients. - P. 163.

4. Burden of adhesions in abdominal and pelvic surgery: systematic review and met-analysis / R. P. Ten Broek, Y. Issa, E. J. van Santbrink [et al.] // BMJ. - 2013. - Vol. 347. - P. f5588.

5. NELA Project Team. The second patient report of the National Emergency Laparotomy Audit (NELA). London: The Royal College of Anaesthetists. - 2016.

6. Use of national burden to define operative emergency general surgery / J. W. Scott, O. A. Olufajo, G. A. Brat [et al.] // JAMA Surg. - 2016. - Vol. 151 (6). e160480.

7. The public health burden of emergency general surgery in the United States: a 10-year analysis of the nationwide inpatient sample - 2001 to 2010 / S. C. Gale, S. Shafi, V. Y. Dombrovskiy [et al.] // J. Trauma Acute Care Surg. - 2014. - Vol. 77 (2). - P. 202-208.

8. Nationwide investigations of intestinal obstruction in Japan / J. Shikata, K. Ohtaki, K. Amino, Y. Takeda // Jpn. J. Surg. 1990. - Vol. 20 (6). - P. 660-664.

9. Impact of introduction of an acute surgical unit on management and outcomes of small bowel obstruction / A. M. Musiienko, R. Shakerian, A. Gorelik [et al.] // ANZ J. Surg. - 2016. - Vol. 86
Висновки. Досягти покращення результатів можна при використанні комплексного підходу до профілактики і лікування хвороби зрощень очеревини, використанні сучасних і нових протиспайкових препаратів.

Перспективи подалыших досліджень. 3'явилися публікації щодо ефективності використання нових протизлукових препаратів на основі ікодестрину. Також потрібно вивчити роль імуномодуляторів в профілактиці злукової хвороби очеревини.

(10). - P. 831-835.

10. Bologna guidelines for diagnosis and management of adhesive small bowel obstruction (ASBO): 2013 update of the evidencebased guidelines from the world society of emergency surgery ASBO working group / Richard P. G. ten Broek, P. Krielen, S. Di Saverio [et al.] // World J. Emerg. Surg. - 2018. - Vol. 13-24. 11. Bologna guidelines for diagnosis and management of adhesive small bowel obstruction (ASBO): 2013 update of the evidencebased guidelines from the world society of emergency surgery ASBO working group / S. Di Saverio, F. Coccolini, M. Galati [et al.] // World J. Emerg. Surg. - 2013. - Vol. 8 (1). - P. 42.

12. P.O.P.A. study: prevention of postoperative abdominal adhesions by icodextrin $4 \%$ solution after laparotomy for adhesive small bowel obstruction. A prospective randomized controlled trial / F. Catena, L. Ansaloni, S. Di Saverio, A. D.Pinna // J. Gastrointest. Surg. - 2012. - Vol. 16 (2). - P. 382-388.

13. Laparoscopic versus open adhesiolysis for small bowel obstruction - a multicenter, prospective, randomized, controlled trial / V. Sallinen, H. Wikström, M. Victorzon [et al.] // BMC Surgery. - 2014. - Vol. 14. - P. 77. Access mode : <http://www. biomedcentral.com/1471-2482/14/77.

14. Efficacy and safety of Seprafilm for preventing postoperative abdominal adhesion: systematic review and metaanalysis / Q. Zeng, Z. Yu, J. You, Q. Zhang // World J. Surg. - 2007. Vol. 31, No. 11. - P. 2125-2131.

15. Блинников О. И. Лапароскопические операции при острой спаечной кишечной непроходимости у детей / О. И. Блинников, А. Ф. Дронов, А. Н. Смирнов // Лапароскопическая хирургия. - М., 1993. - С. 82-87.

\section{REFERENCES}

1. Brochhausen, C., Schmitt, V.H., \& Hollemann, D. (2012). Current strategies and future perspectives for intraperitoneal adhesion prevention. J. Gastrointest. Surg., 16, 1256-1274.

2. Rajab, T.K., Wallwiener, M., Talukdar, S., Kraemer, B., Adhesion Ouassi, M., Gaujoux, S., \& Veyrie, N. (2012). Post-operative adhesions after digestive surgery: their incidence and prevention: review of the literature. J. Visc. Surg., 149, 104-114.

3. Antibiotic Guidelines 2015-2016 - Johns Hopkins. Treatment Recommendations For Adult Inpatients.

4. Ten Broek, R.P., Issa, Y, van Santbrink, E.J., Bouvy, N.D., Kruitwagen, R.F., \& Jeekel, J. et al. (2013). Burden of adhesions in abdominal and pelvic surgery: systematic review and metanalysis. BMJ, 347, f5588.

5. (2016). NELA Project Team. The second patient report of the

National Emergency Laparotomy Audit (NELA). London: The Royal College of Anaesthetists.

6. Scott, J.W., Olufajo, O.A., Brat, G.A., Rose, J.A., Zogg, C.K., \& Haider, A.H. (2016). Use of national burden to define operative emergency general surgery. JAMA Surg., 151 (6). e160480.

7. Gale, S.C., Shafi, S., Dombrovskiy, V.Y., Arumugam, D., \& Crystal, J.S. (2014). The public health burden of emergency general surgery in the United States: a 10-year analysis of the nationwide inpatient sample - 2001 to 2010. J. Trauma Acute Care Surg., 77 (2), 202-208.

8. Shikata, J., Ohtaki, K., Amino, K., \& Takeda, Y. (1990). Nationwide investigations of intestinal obstruction in Japan. Jpn. J. Surg., 20 (6), 660-664.

9. Musiienko, A.M., Shakerian, R., Gorelik, A., Thomson, B.N., 
Skandarajah, A.R. (2016). Impact of introduction of an acute surgical unit on management and outcomes of small bowel obstruction. ANZ J. Surg., 86 (10), 831-835.

10. Richard, P.G. ten Broek, Krielen, P., Di Saverio, S., Coccolini, F., Biffl, W., et al. (2018). Bologna guidelines for diagnosis and management of adhesive small bowel obstruction (ASBO): 2013 update of the evidence-based guidelines from the world society of emergency surgery ASBO working group. World J. Emerg. Surg., 13-24.

11. Di Saverio, S., Coccolini, F., Galati, M., Smerieri, N., Biffl, W.L., \& Ansaloni, L. et al. (2013). Bologna guidelines for diagnosis and management of adhesive small bowel obstruction (ASBO): 2013 update of the evidence-based guidelines from the world society of emergency surgery ASBO working group. World J. Emerg. Surg., 8 (1), 42.

12. Catena, F., Ansaloni, L., Di Saverio, S., \&Pinna, A.D. (2012). P.O.P.A. study: prevention of postoperative abdominal adhesions by icodextrin $4 \%$ solution after laparotomy for adhesive small bowel obstruction. A prospective randomized controlled trial. $J$. Gastrointest. Surg., 16 (2), 382-388.

13. Sallinen, V., Wikström, H., Victorzon, M., Salminen, P., Koivukangas, V., Haukijärvi, E., Enholm, B., Leppäniemi, A., \& Mentula, P. (2014). Laparoscopic versus open adhesiolysis for small bowel obstruction - a multicenter, prospective, randomized, controlled trial. BMC Surgery, 14, 77. Retrieved from: http:// www.biomedcentral.com/1471-2482/14/77.

14>. Zeng, Q., Yu, Z., You, J., \& Zhang, Q. (2007). Efficacy and safety of Seprafilm for preventing postoperative abdominal adhesion: systematic review and metaanalysis. World J. Surg., 31 (11), 2125-2131.

15. Blinnikov, O.I., Dronov, A.F., \& Smirnov, A.N. (1993). Laparoscopicheskiye operatsii pri ostroy spayechnoy kishechnoy neprokhodimosti u detey [Laparoscopic surgery for acute adhesive intestinal obstruction in children]. Laparoskopicheskaya khirurgiya - Laparoscopic Surgery, 82-87 [in Russian].

Отримано 19.11.2019

Електронна адреса для листування: s.1.tvfly@gmail.com

\title{
O. V. PYPTIUK, S. B. TELEMUKHA
}

Ivano-Frankivsk National Medical University

\section{EFFICIENCY OF ANTI-ADHESIVE DRUGS IN PLANNED AND URGENT ENTEROLISE}

\begin{abstract}
The aim of the work: to study and compare the results of treatment of patients with adhesive disease of the peritoneum after planned and urgent surgical interventions that underwent adhesolysis and used the Defensal drug. One of the ways to prevent postoperative adhesions is not only the development of modern methods of surgical interventions, intact suture materials and modern implants, but also the search for new methods of preventing postoperative adhesions using anti-adhesive preparations.

Materials and Methods. During the period from 2013 to 2019, 80 patients with adhesive disease were examined and treated, and adhesions were separated, aged 21 to 79 years. Patients were divided into the following groups: 1) the control group included 20 patients who underwent planned surgical and conservative treatment with generally accepted methods with peritoneal joint disease, large incisional hernias; 2) group 2 (20 patients) - planned surgical intervention and separation of adhesions using Defensal drug; 3) group 3 - of 20 patients who underwent acute enterolysis without the use of Defensal with acute commissural small bowel obstruction; 4) group 4 of 20 patients who underwent acute enterolysis with the use of Defensal with acute commissural small bowel obstruction. Results and Discussion. Good immediate, short-term and long-term results with a follow-up period of up to 6 years were obtained in group 2 after planned surgical interventions and the use of Defensal. However, in group 4 of patients after urgent enterolysis and use of the drug, an improvement in immediate results is visible, however, long-term results practically do not differ from the group 3 of patients. You can achieve better results by using an integrated approach to the prevention and treatment of peritoneal commissural disease, the use of modern and new anti-adhesive drugs.
\end{abstract}

Key words: adhesive disease; Defensal drug, enterolise.

\author{
А. В. ПЫПТЮК, С. Б. ТЕЛЕМУХА
}

Ивано-Франковский национальный медицинский университет

\section{ЭФФЕКТИВНОСТЬ ПРОТИВОСПАЕЧНЫХ ПРЕПАРАТОВ В ПЛАНОВОМ И УРГЕНТНОМ ЭНТЕРОЛИЗЕ}

\footnotetext{
Цель работы: изучить и сравнить результаты лечения больных со спаечной болезнью брюшины после плановых и ургентных оперативных вмешательств, которым проведено адгеолиз и использовано препарат “Дефенсаль”. Одним из путей профилактики послеоперационных спаек является не только разработка современных методов оперативных вмешательств, интактных шовных материалов и современных имплантатов, а поиск новых методов предотвращения послеоперационных спаек с помощью противоспаечных препаратов.

Материалы и методы. За период с 2013 по 2019 годы обследовано и пролечено 80 больных с спаечный болезнью, которым проведено разъединения спаек, в возрасте от 21 до 79 лет. Больные разделены на следующие группы: 1) в группу контроля
} 


\section{З ДОСВІДУ РОБОТИ}

вошли 20 больных, которым с болезнью сращений брюшины, инцизионными грыжами больших размеров, проведено плановое оперативное и консервативное лечение общепринятыми методиками; 2) во второй группе - (20 больных) проведено плановое оперативное вмешательство и разъединение спаек с использованием препарата “Дефенсаль”; 3) в третьей группе 20 больных, которым с острой спаечной тонкокишечной непроходимостью проведен ургентный ентеролиз без использования препарата Дефенсаль; 4) в четвертой группе 20 больных, которым с острой спаечной тонкокишечной непроходимостью проведен ургентный энтеролиз с использованием препарата “Дефенсаль”.

Результаты исследований и их обсуждение. Хорошие непосредственные, краткосрочные и отдаленные результаты сроком наблюдения до 6 лет получено во второй группе после проведения плановых оперативных вмешательств и использования препарата “Дефенсаль”. Однако в четвертой группе больных после ургентного энтеролиза и использования препарата видно улучшение непосредственных результатов, однако отдаленные результаты практически не отличаются от третьей группы больных. Добиться улучшения результатов можно при использовании комплексного подхода к профилактике и лечению спаечной болезни брюшины, использовании современных и новых противоспаечных препаратов.

Ключевые слова: спаечная болезнь; препарат “Дефенсаль”; энтеролиз. 